\title{
Avances biotecnológicos en el diagnóstico de enfermedades infecciosas
}

\author{
Fidel de la Cruz Hernández-Hernández, Dr en C,(1) Mario H Rodríguez, MC, PhD.(2)
}

\begin{abstract}
Hernández-Hernández FC, Rodríguez MH. Avances biotecnológicos en el diagnóstico de enfermedades infecciosas.

Salud Publica Mex 2009;5 I supl 3:S424-S438.
\end{abstract}

\section{Resumen}

La detección de moléculas de patógenos (antígenos y material genético) y moléculas de respuesta de los hospederos ante la infección (anticuerpos) es el principio básico de las pruebas diagnósticas moleculares. Estas pruebas han hecho innecesaria la detección directa del microorganismo patógeno agresor. Los nuevos avances en biología molecular y el desarrollo de tecnología robótica y secuenciación genómica y proteica han permitido el desarrollo de nuevas pruebas diagnósticas altamente específicas y de gran rendimiento. La genómica y proteómica contribuyen a la identificación de biomarcadores y la biotecnología aporta métodos para producir reactivos de alta pureza. La identificación de genes codificantes de antígenos específicos, su clonación y producción recombinante y la producción de anticuerpos monoclonales, fragmentos de éstos y anticuerpos de una sola cadena han hecho posible el desarrollo de nuevas técnicas inmunológicas más seguras y de sensibilidad y especificidad elevadas. Nuevas moléculas de reconocimiento, incluidos los aptámeros, podrán pronto superar la necesidad de producir anticuerpos mediante inmunización. Para la detección de material genético se han desarrollado nuevas medidas metodológicas basadas en la hibridación y amplificación (PCR, de punto final y en tiempo real) en formatos multiplex $y$ en microarreglos y para su detección se han diseñado moléculas reporteras que permiten su cuantificación. Aunque estos métodos requieren instrumentación compleja, puede ya anticiparse que pronto serán accesibles para su aplicación en salud pública.

Palabras clave: biotecnología; diagnóstico; enfermedades infecciosas; PCR; anticuerpos; espectrometría de masas

\author{
Hernández-Hernández FC, Rodríguez MH. \\ Biotechnological advances \\ in infectious diseases diagnosis.
}

Salud Publica Mex 2009;5 I suppl 3:S424-S438.

\section{Abstract}

The detection of molecules of pathogens (antigens and genetic material) and host molecules in response to infections (antibodies) is the basic principle involved in molecular diagnostic tests. These tests have avoided the need to detect the attacking pathogen. New advances in molecular biology and the development of robotic technology and genomic and protein sequencing have allowed for the development of new high performance and highly specific tests. Genomics and proteomics contribute to the identification of biomarkers and biotechnology provides methods to produce high purity reagents. The identification of coding genes of specific antigens, their cloning and recombinant production, the production of monoclonal antibodies, their fragments and single chain antibodies enabled new, safer, high sensitivity and specificity immunological techniques to develop. New recognition molecules, including aptamers, will soon replace the need to produce antibodies by immunization. For the detection of genetic material, new methodological strategies based on hybridization and amplification (PCR, end point and real time) in multiplex and microarray formats have been developed, and for their detection new reporter molecules have been designed that enable their quantification.Although these methods require sophisticated instrumentation, they will soon be accessible for application in public health.

Key words: biotechnology; diagnosis; infectious diseases; PCR; antibodies; mass spectrometry

(I) Departamento de Infectómica y Patogénesis Molecular, CINVESTAV-IPN. Zacatenco, México DF, México.

(2) Centro de Investigación sobre Enfermedades Infecciosas, Instituto Nacional de Salud Pública. Cuernavaca, Morelos, México.

Fecha de recibido: 28 de julio de 2008 - Fecha de aceptado: 26 de marzo de 2009

Solicitud de sobretiros: Dr. Mario H. Rodríguez. Centro de Investigaciones sobre Enfermedades Infecciosas, Instituto Nacional de Salud Pública. Av. Universidad 655, col. Santa María Ahuacatitlán. 62100 Cuernavaca Morelos, México.

Correo electrónico: mhenry@correo.insp.mx 
L a eficacia de los métodos para el diagnóstico de las senfermedades infecciosas depende de su sensibilidad y especificidad para la detección inequívoca de la presencia de organismos patógenos o la respuesta específica del hospedero infectado ante su presencia. Las nuevas tecnologías basadas en la biología molecular ha permitido la identificación de componentes (biomarcadores) exclusivos de los agentes infecciosos (bacterias, protozoarios, virus), moléculas que participan en la interacción de los patógenos con sus hospederos (de reconocimiento e interacción con sus células y organismos blanco, productos metabólicos y toxinas) y moléculas que producen los hospederos en respuesta a la agresión. Éstas pueden utilizarse para la detección e identificación, a nivel de grupo y especie, de los agentes agresores y son la base para el diseño de pruebas diagnósticas moleculares. Para este efecto, los nuevos desarrollos en biotecnología han posibilitado la ingeniería molecular de reactivos para pruebas que dependen de la interacción de moléculas de reconocimiento, la producción a gran escala de reactivos altamente purificados, el desarrollo de pruebas más sensibles con alta especificidad y la automatización de protocolos diagnósticos para el procesamiento simultáneo de un número grande de muestras, lo cual las hace útiles en estudios de salud pública. ${ }^{1}$

\section{Detección específica de moléculas mediante pruebas inmunológicas}

Las pruebas inmunológicas están diseñadas para detectar antígenos circulantes de los patógenos o la presencia de anticuerpos producidos en respuesta a agentes infecciosos. Algunas de las moléculas que participan en la interacción hospedero-parásito pueden permanecer en el suero de los sujetos infectados por periodos prolongados y son detectables aun en casos en los que la infección es asintomática y después de su resolución. La detección de estas moléculas, si bien no siempre es útil para identificar infecciones activas, lo es para determinar su frecuencia y el grado de dispersión de los agentes infecciosos en la población humana.

La detección de antígenos circulantes en una persona es prueba fehaciente de una infección activa o muy reciente; la presencia de anticuerpos específicos es evidencia de que el agente microbiano se encuentra o estuvo presente en ese individuo, por lo que su reconocimiento puede servir como prueba diagnóstica de una infección aguda o reciente (IgM), o bien de una infección pasada o crónica $(\operatorname{IgG}){ }^{2}$

En la práctica, las mayores limitaciones para el diseño y desarrollo de nuevos sistemas de diagnóstico por métodos inmunológicos son la producción de antígenos y anticuerpos específicos para las moléculas de interés.
La producción de proteínas y secuencias nucleotídicas por medio de técnicas de biología molecular hace posible la obtención de reactivos de alta pureza en grandes cantidades. De manera adicional, la estructura de las moléculas producida por estas técnicas puede modificarse para incrementar su reactividad. La preparación de anticuerpos específicos requiere antígenos en cantidad y pureza suficientes. Si bien los antígenos proteicos pueden obtenerse directamente del organismo que se desea detectar en la prueba diagnóstica, el uso de moléculas producidas por metodología recombinante tiene varias ventajas: ${ }^{3}$ dado que se conoce la secuencia del gen y su producto correspondiente, es posible introducir en estas secuencias modificaciones que al cambiar algún grupo químico específico facilitan su purificación, o la hacen más antigénica y por tanto más eficiente para la producción de anticuerpos específicos. Además, la producción de antígenos por medio de tecnología recombinante permite aumentar la cantidad y pureza del antígeno producido, además de acelerar y disminuir los costos de producción. ${ }^{4,5}$ Por otra parte, los antígenos de microorganismos peligrosos pueden producirse en organismos inocuos, con lo que se reduce el riesgo de infección durante la producción. 5,6

Entre las pruebas inmunológicas más utilizadas en métodos diagnósticos figuran las de hemaglutinación, inmunodifusión e inmunofluorescencia indirecta (IFI); algunas de éstas constituyen las pruebas de referencia ("estándar de oro") para la detección de agentes patógenos. ${ }^{7}$ En la actualidad se utilizan los métodos automatizados en cámaras de multipozos tipo ELISA y las pruebas rápidas (rapid diagnostic tests, RDT), en las cuales los antígenos a detectar se fijan a una tira de membrana que se sumerge directamente en los reactivos de detección (anticuerpos) y revelado, con obtención en pocos minutos de un resultado. Estas pruebas permiten procesar en forma expedita un número elevado de muestras, con buena sensibilidad y especificidad.

El análisis del desarrollo de pruebas rápidas (RDT) ejemplifica los procedimientos moleculares empleados para el diseño de nuevas técnicas inmunológicas, así como las ventajas y limitaciones de este tipo de pruebas para el diagnóstico de enfermedades infecciosas, incluidas malaria, SIDA y sífilis. Las RDT son tiras diagnósticas que tienen como principio la inmunocromatografía para identificar antígenos o anticuerpos; un reactivo (antígeno o anticuerpo) es reconocido por otro reactivo (anticuerpo o antígeno) contenido en un líquido que migra a través del papel. El objetivo de estas pruebas es contar con instrumentos diagnósticos que sean simples, con resultados inmediatos para el diagnóstico in situ (junto al paciente) y, de esa manera, poder instituir tratamiento oportuno (por tal razón se conocen como pruebas de punto de atención), y al mismo tiempo 
tomar decisiones acerca del control de la dispersión de los agentes patógenos.

Las tiras diagnósticas son producto de la aplicación de la biología molecular a varios niveles, la identificación de biomarcadores específicos, su clonación y producción por medio de tecnología recombinante y la producción de anticuerpos monoclonales para su captura y detección. El caso de las RDT para la detección de pacientes maláricos es un buen ejemplo. El diagnóstico de infección con el parásito de la malaria (Plasmodium spp.) se basa en la identificación de un biomarcador como la proteína rica en histidinas 2 (PRH2), la enzima deshidrogenasa de lactato (pLDH) o una aldolasa parasitaria. ${ }^{8,9}$ Las tiras diagnósticas contienen en su extremo distal anticuerpos monoclonales que reconocen $\mathrm{pLDH}$ o aldolasa, comunes entre las especies del parásito, pero todas contienen anticuerpos específicos contra P. falciparum, de tal modo que pueden servir para establecer diagnósticos diferenciales o de infecciones mixtas.

Para el diagnóstico se coloca en el extremo proximal de la tira la muestra sanguínea, junto con un amortiguador de lisis celular que contiene además un anticuerpo marcado con un colorante. La migración del líquido pone en contacto a los tres reactivos y la fijación en una banda del anticuerpo marcado ${ }^{10}$ (figura 1). La presencia

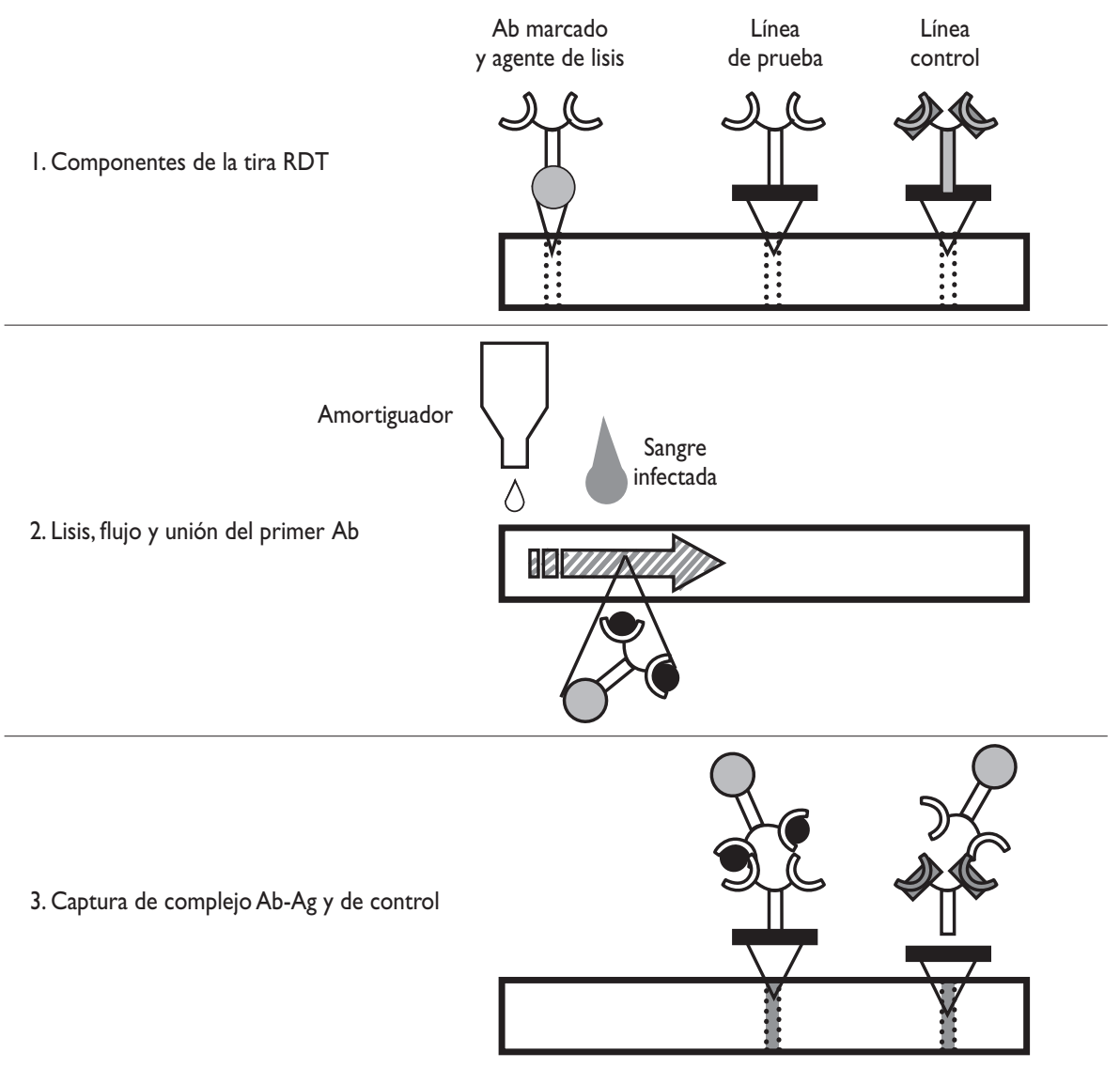

Figura I. Pruebas diagnósticas rápidas (rapid diagnostic test, RDT). I. Sobre una membrana porosa se trazan tres LÍNEAS; EN LA PRIMERA SE FIJA UN ANTICUERPo (AB) DIRIGIDO CONTRA EL ANTÍGENO BLANCO DEL PARÁsito (AG) Y SE MARCA CON UNA ENZIMA; EN LA SEGUNDA, LLAMADA DE PRUEBA, SE FIJA UN ANTICUERPO DIRIGIDO CONTRA EL ANTÍGENO BLANCO DEL PARÁSITO Y EN LA TERCERA, O CONTROL, SE FIJA TAMBIÉN UN ANTICUERPO DIRIGIDO CONTRA EL ANTICUERPO MARCADO. 2. EL EXTREMO DE LA TIRA SE HIDRATA CON UNA SOLUCIÓN AMORTIGUADORA QUE FLUYE A LO LARGO DEL SISTEMA, EL AGENTE DE LISIS SOLUBILIZA Y LIBERA LOS AG Y EL AB MARCADO, LO CUAL HACE POSIBLE LA FORMACIÓN DE COMPLEJOS QUE SON ARRASTRADOS A LO LARGO DE LA TIRA. 3. LOS COMPLEJOS AB-Ag SON CAPTURADOS EN LA LíNEA DE PRUEBA Y LOS ANTICUERPOS LIBRES EN LA LÍNEA CONTROL. EN PRESENCIA DE UN CROMÓGENO, SUSTRATO DE LA ENZIMA UNIDA AL ANTICUERPO, SE DESARROLLAN LÍNEAS QUE REPORTAN EL RECONOCIMIENTO DEL ANTICUERPO. LA LíNEA CONTROL DEBE EMITIR SEÑAL SIEMPRE PARA GARANTIZAR LA INTEGRIDAD DE LOS REACTIVOS. LA SEÑAL EN LA LíNEA DE PRUEBA INDICA LA PRESENCIA DEL PARÁSITO 
de pLDH o aldolasa en la muestra sanguínea indica infección activa, pero la PRH2 persiste en circulación hasta por 14 días después del tratamiento, por lo que en ese caso puede tratarse de una infección resuelta o persistente. La sensibilidad de la prueba es de $95 \%$, en comparación con un análisis por microscopia, con un límite inferior de 100 parásitos/ $\mu 1 .{ }^{8}$ Sin embargo, existen variaciones regionales de HPR2, lo que hace que en algunas áreas la prueba genérica no reconozca parasitemias por debajo de 500 parásitos / $\mu \mathrm{l}$.

Varias pruebas de la efectividad y el costo-beneficio de las RTD se han realizado en varias partes del mundo. Por ejemplo, debido al aumento de la resistencia de los parásitos del paludismo a los medicamentos anti-maláricos, se han introducido nuevos esquemas de tratamiento con combinaciones farmacológicas que requieren una evaluación oportuna de su efectividad; para ello las RTD proporcionan ventajas en relación con el manejo rápido y masivo de muestras para la detección parasitaria. ${ }^{11,12}$

La disponibilidad de aparatos robóticos ha posibilitado la manipulación automatizada de cantidades muy pequeñas de reactivos y la fijación de moléculas reactivas (ácidos nucleicos, proteínas o azúcares) en hileras, muy próximas entre sí, sobre una matriz sólida plana (una membrana o un vidrio), lo que se denomina microarreglos ${ }^{13}$ (figura 2). Para el desarrollo de pruebas diagnósticas existen dos tipos de microarreglos de proteínas: los que contienen fijados en la matriz sólida anticuerpos para la detección de diversos antígenos (biomarcadores de patógenos) y los que contienen antígenos específicos de los patógenos para la detección de anticuerpos en muestras sanguíneas. Un ejemplo de estos últimos se desarrolló para la detección simultánea de anticuerpos en sueros humanos contra Toxoplasma gondii, el virus de la rubeola, citomegalovirus y el virus del herpes simple tipos 1 y $2 .{ }^{14} \mathrm{El}$ desempeño diagnóstico de estos microarreglos se comparó con el de una prueba ELISA comercial, lo cual puso de manifiesto las ventajas de este tipo de pruebas de alto desempeño respecto de las técnicas inmunológicas tradicionales: ambas pruebas pueden utilizarse para el diagnóstico de infecciones recientes (detección de IgM), pero en los microarreglos, además de la investigación simultánea de varios patógenos, la reproducibilidad de los resultados es mayor, se utilizan cantidades de reactivos menores y, por último, la incorporación de curvas de calibración en la matriz permite que ésta se procese bajo las mismas condiciones que las muestras, de tal modo que se eliminan las variaciones debidas al tiempo de manipulación, temperatura, contenido de grasa, proteínas, y otros factores, en los sueros problema.
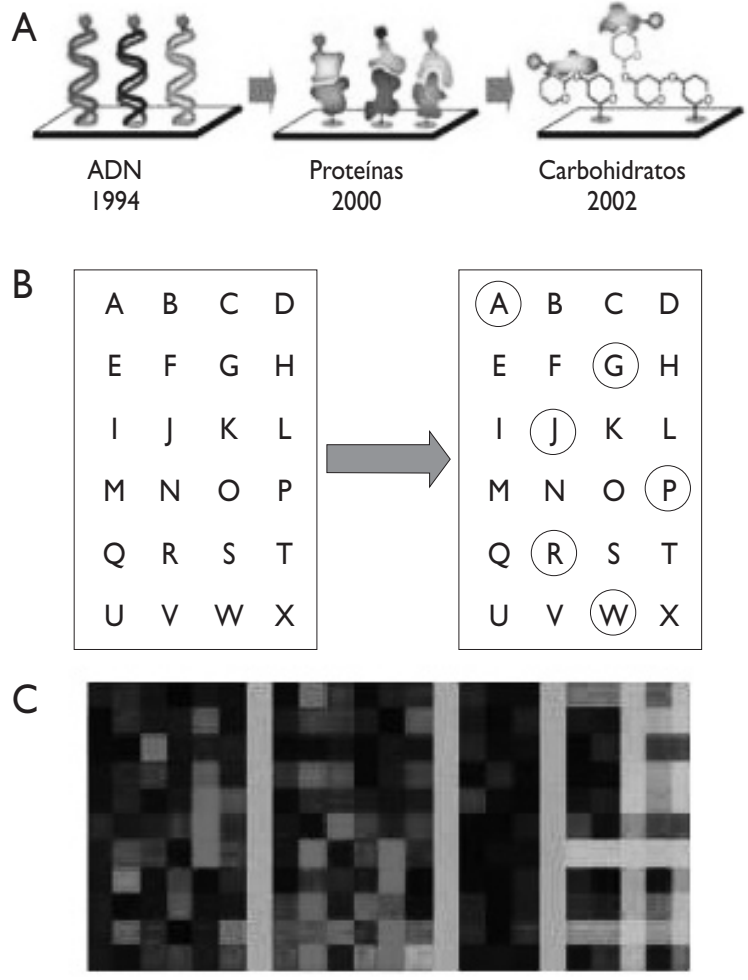

Figura 2. Microarreglos. A. en una matriz sólida se FIJA UNA COLECCIÓN DE MOLÉCULAS ACOMODADAS EN FORMA DE HILERAS PARALELAS (MICROARREGLOS) QUE FORMAN UN PUNTO MUY PEQUEÑO Y CON UNA LOCALIZACIÓN CONOCIDA. ESTAS MOLÉCULAS PUEDEN SER ADN (AÑo 1994), PROTEÍNA (2000) O AZÚCARES (2002). B. A LA MATRIZ SE LE AÑADE UNA SOLUCIÓN "SONDA" CON UNA MEZCLA DE MOLÉCULAS QUE POR AFINIDAD SE PEGAN A LAS QUE ESTÁN UNIDAS A LA MATRIZ. ESTA MEZCLA PUEDE CONTENER ÁCIDOS NUCLEICOS O PROTEÍNAS QUE SE MARCAN, CASI SIEMPRE CON FLUORESCENCIA, LO QUE PERMITE SU DETECCIÓN Y MEDICIÓN POR FLUORÓMETROS AUTOMATIZADOS EN LOS PUNTOS DONDE SE UNIERON. C. ESTE FORMATO PERMITE ANALIZAR UNA GRAN CANTIDAD DE MOLÉCULAS A LA VEZ. EL SISTEMA PERMITE CALCULAR LA CANTIDAD DE LAS MOLÉCULAS SONDA FIJADAS A LA MATRIZ Y LAS DESPLIEGA COMO CUADROS DE COLORES.

\section{Ingeniería molecular de anticuerpos}

Los anticuerpos se unen con alta especificidad y sensibilidad a proteínas, azúcares, lípidos y moléculas diversas; en consecuencia, usados como reactivos, pueden identificar de forma eficaz una gran variedad de biomarcadores de agentes patógenos. No obstante, éstos presentan algunas 
dificultades de producción e inconvenientes para las aplicaciones biotecnológicas. Por consiguiente, la producción tradicional de anticuerpos contra el antígeno deseado, por medio de inmunizaciones de animales, no siempre es exitosa; asimismo, es posible que la especificidad y la sensibilidad de los anticuerpos producidos puede ser limitada por las características genéticas de la especie animal utilizada. ${ }^{15,16} \mathrm{Si}$ bien la tecnología recombinante ha revolucionado la producción, diseño y adecuación para funciones específicas de proteínas, la estructura de los anticuerpos formada por dos cadenas pesadas y dos ligeras dificulta su producción por medio de esta tecnología. Además, estas moléculas requieren modificaciones postraduccionales, como glucosilación, doblamiento y formación de puentes disulfuro, lo que impide su producción en forma recombinante en organismos procariontes. La metodología para la preparación de anticuerpos monoclonales revolucionó la producción de anticuerpos, ya que hace posible obtener anticuerpos dirigidos contra un solo epitopo, se pueden almacenar las células para volver a elaborarlos cuando sea necesario y se pueden producir cantidades suficientes de reactivos. ${ }^{17,18}$ No obstante, esta medida es todavía costosa y encarece su inclusión en pruebas diagnósticas.

Varias intervenciones moleculares se han empleado para resolver las limitaciones de producción y el diseño de anticuerpos con mayor afinidad por sus antígenos y estructuras más sencillas y estables. Las cadenas pesadas (VH) y ligeras (VL) que conforman los anticuerpos pueden producirse de manera aislada y conservar su capacidad de unirse de manera específica a sus antígenos, ${ }^{19,20}$ pero con afinidad y solubilidad reducidas. ${ }^{21}$ Las moléculas que contienen aparejadas las regiones complementarias (CDR) de las cadenas VH y VL son suficientes para mantener su unión específica a los antígenos. ${ }^{22}$ Los métodos de biología molecular se emplean para generar proteínas semisintéticas derivadas de los anticuerpos, ${ }^{23,24}$ estructuralmente más sencillas, que incluyen las regiones variables funcionales, con capacidad de unión a un antígeno y estables en diversas condiciones ambientales; entre éstas figuran las siguientes: fragmentos ab $(\mathrm{Fab}) ;{ }^{25}$ fragmentos variables $(\mathrm{Fv}) ;{ }^{26}$ y regiones variables conformadas con una sola cadena (scFv). ${ }^{27}$ Estas moléculas se producen como fragmentos Fab de anticuerpos monovalentes, como cadenas únicas (SCFv) que contienen las regiones $\mathrm{VH}$ y VL unidas por un polipéptido puente y que mantienen su funcionalidad, como por ejemplo su capacidad de inhibir el desarrollo de patógenos. ${ }^{28}$ Las moléculas formadas por un solo dominio variable $\left(\mathrm{V}_{\mathrm{H}}^{\mathrm{s}}\right)$ se pueden diseñar por computadora para hacerlas complementarias a la estructura de su molécula blanco. ${ }^{29-31}$ También se producen fragmentos correspondientes a las regiones variables de los anticuerpos conformados con dos cadenas peptídicas ensambladas en una sola cadena peptídica (dsFv). ${ }^{30,31}$ Algunas de estas variantes de anticuerpos se producen a gran escala en organismos modelo como Escherichia coli o sistemas de virus, procariotes y eucariotes. ${ }^{32,33} \mathrm{La}$ producción de fragmentos de proteínas en bacteriófagos filamentosos de tipo f (fagos f1, fd y M13) también se ha empleado para la elaboración de scFvs, para cuyo fin se clona el fragmento de interés para producirla fusionada con una proteína de cápside expuesta en la superficie del virión (phage display) (figura 3). ${ }^{34}$ Los fagos son muy convenientes para expresar dominios de anticuerpos, ya que son estables en forma cristalizada o liofilizada y ello facilita su almacenaje y transporte y se pueden producir en gran cantidad y a bajo costo. Ejemplos de la aplicación de esta tecnología son la producción de fagos capaces de identificar antígenos de bacterias del género Bacillus spp., incluido B. anthracis, los cuales tienen alto potencial para diagnóstico ya que son específicos y sensibles y se pueden manipular en diversas plataformas de ensayos diagnósticos ${ }^{35,36}$ y se experimenta con fagos útiles para la neutralización de ataques terroristas, ya que se ha demostrado que la inmunización pasiva tiene efectos significativos en el tratamiento. ${ }^{37,38}$

Una alternativa para la producción de nuevos reactivos de reconocimiento es la ingeniería de moléculas (proteínas y otras moléculas) diferentes de las Igs, con capacidad de unirse de manera específica a un antígeno. Una ventaja adicional de estos moldes es que pueden generarse moléculas que no tengan reacciones inmunitarias cruzadas y que para el revelado de sus pruebas no dependan, a su vez, de segundos anticuerpos que puedan presentar reconocimiento cruzado. Entre estas moléculas se encuentran las proteínas ricas en leucina, lipocalinas y tendamistat. ${ }^{39}$

Por otra parte, por medio de la síntesis química de oligonucleótidos, se generan moléculas de ARN y ADN (genes sintéticos), con propiedades de reconocimiento altamente específico de moléculas que en algunos casos es superior al de los anticuerpos. ${ }^{40}$ Los aptámeros son muy estables ante condiciones ambientales, pueden producirse contra moléculas poco inmunogénicas y su afinidad y especificidad de unión a los antígenos pueden mejorarse clonando los aptámeros como genes sintéticos y la introducción dirigida de variaciones en su secuencia "evolución dirigida". Por otra parte, durante la síntesis de los aptámeros se pueden introducir átomos que funcionan como etiquetas para su detección como los quantum dots (Q-dots) y al aplicarse se puede inducir su unión covalente al sitio blanco, lo que permite que el complejo aptámero-molécula blanco pueda lavarse en condiciones extremas, antes de su lectura, para mejorar la especificidad y estabilidad de las pruebas diagnósti- 
A

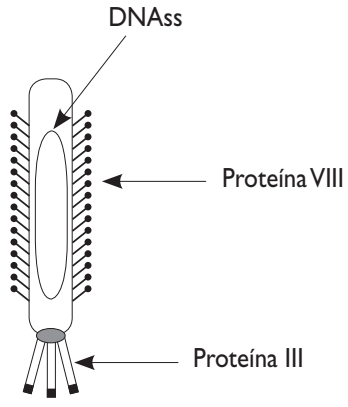

B

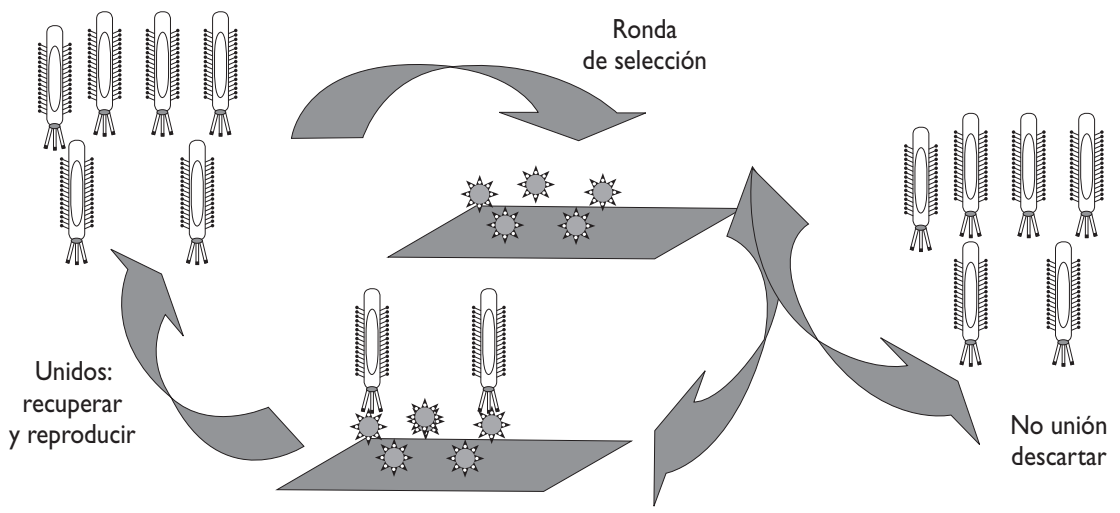

Figura 3. Despliegue de proteínas en fagos. A. en el ADN de un fago filamentoso como MI 3 Se clona (anidada denTRO DE LA SECUENCIA DE LAS PROTEÍNAS DE CÁPSIDE III O VII) LA SECUENCIA DE UNA PROTEÍNA HETERÓLOGA, DE TAL MOdO QUE AL PRODUCIRSE NUEVAS PARTíCULAS VIRALES ÉSTAS PRESENTAN EN SU SUPERFICIE EL FRAGMENTO DE LA PROTÉ́NA QUE SE CLONó. B. AL CLONAR EN LOS FAGOS UNA POBLACIÓN DE ADNC QUE CODIFIQUE LA REGIÓN DE RECONOCIMIENTO DE UN ANTICUERPO, UNA POR FAGO, Y CADA SECUENCIA CON LIGERAS DIFERENCIAS GENERADAS AL AZAR, SE GENERA UNA POBLACIÓN DE FAGOS TAL QUE CADA UNO DESPLIEGA UNA PROTEÍNA DIFERENTE. ESTA POBLACIÓN SE PUEDE SELECCIONAR POR SU UNIÓN A UN ANTÍGENO ESPECÍFICO, PARA OBTENER LOS FAGOS QUE EXPRESAN LAS MOLÉCULAS CON MAYOR AFINIDAD A LA MOLÉCULA BLANCO. ESTOS FAGOS SE RECUPERAN Y SE MULTIPLICAN PARA OBTENER CANTIDADES ÚTILES DE VIRUS QUE SE ADHIEREN A UN SUSTRATO ESPECÍFICO

cas. Los aptámeros son eficientes en pruebas y formatos bien establecidos y pueden competir con los anticuerpos en diagnóstico e investigación. ${ }^{41-44}$

\section{Biología molecular de ácidos nucleicos y métodos diagnósticos}

Si bien los organismos comparten de manera variable en su genoma genes comunes (ortólogos), estos genes y otros no compartidos presentan secuencias específicas de género, especie y cepa que hacen posible su identificación inequívoca. Una vez identificadas las secuencias exclusivas de patógeno, éstas pueden utilizarse para el desarrollo de reactivos para pruebas diagnósticas. En la práctica se desarrollan de forma constante nuevos equipos para la manipulación, secuenciación y detección de ácidos nucleicos, lo que permite que esté en desarrollo una gran cantidad de proyectos de secuenciación de genomas de microorganismos; de igual modo, muchas de las bases de datos generadas, completas o en proceso, y las herramientas informáticas para su análisis están disponibles libremente en internet (Portal NCBI National Institute for Biotechnology Information, http:/ / www.ncbi.nlm.nih.gov/ Genomes/). ${ }^{45}$ También están disponibles bases de datos con información sistematizada sobre microorganismos con potencialidad patogénica, según sean la agresividad, potencialidad de dispersión, datos epidemiológicos y técnicos para el diagnóstico de enfermedades infecciosas; estas bases de datos se pueden consultar en línea (http: / / www.cdc.gov/ page.do ${ }^{46}$ (cuadros I a III). 
Detección de ácidos nucleicos. La detección del material genético de un microorganismo en muestras biológicas indica la presencia del patógeno en los sujetos de estudio en el momento de obtener la muestra. Esta detección permite la identificación de infecciones de manera directa sin la necesidad del cultivo del agente patógeno causal y la detección de ARN mensajeros indica que el organismo en cuestión está metabólicamente activo. ${ }^{47}$ Las pruebas diagnósticas basadas en ácidos nucleicos se basan en la detección directa de su presencia por medio de sondas específicas (hibridación), pero también es posible incrementar su sensibilidad por medio de la amplificación de secuencias específicas diagnósticas (reacción en cadena de la polimerasa) del material genético presente en las muestras.
La hibridación se basa en la capacidad de dos cadenas sencillas de ácido nucleico, ADN o ARN, complementarias en su secuencia de bases, de formar enlaces específicos y crear una doble hélice en cualquier combinación: ADN-ADN, ADN-ARN y ARN-ARN. Durante la hibridación una molécula de secuencia conocida (la sonda diagnóstica) "busca" e identifica a su complementaria en una mezcla de moléculas de ácido nucleico, aunque ésta sea muy compleja. La hibridación se puede efectuar en diversos formatos, en solución o con la cadena blanco unida a un soporte sólido o incluso in situ, esto es, en un corte de tejido o un microorganismo completo fijado. La sonda diagnóstica puede producirse por síntesis química o técnicas recombinantes y durante su producción se le incorporan etiquetas para su detección

Cuadro I

Genomas de bacterias representativas de importancia médica humana. Estas bases de datos son aCcesibles en el sitio del National Center for Biotechnology Information (WWW.ncbi.nlm.Nih.gov). Se listan las características generales del organismo:TG, tamaño del Genoma; GCc, Contenido de GC

\begin{tabular}{|c|c|c|c|c|}
\hline ID \# & Microorganismo & TG & GCc & Enfermedad causada \\
\hline 269801 & Bacillus anthracis* & 5.50 & 35.2 & Ántrax \\
\hline 257313 & Bordetella pertussis Tohama I & 4.09 & 67.7 & Síndrome respiratorio \\
\hline 224326 & Borrelia burgdorferi B3I & 1.52 & 28.2 & Enfermedad de Lyme \\
\hline 195099 & Campylobacter jejuni RMI22I * & 1.78 & 31 & Envenenamiento alimenticio \\
\hline 272561 & Chlamydia trachomatis D/UW-3/CX* & 1.04 & 40 & Faringitis, bronquitis y neumonitis \\
\hline 36826 & Clostridium botulinum A * & 3.96 & 28 & Botulismo \\
\hline 212717 & Clostridium tetani E88 & 2.87 & 27 & Tétanos \\
\hline 257309 & Corynebacterium diphtheriae NCTC 13129 & 2.49 & 53.5 & Difteria \\
\hline 216592 & Escherichia coli $536 *$ & 4.9 & 50.5 & Infección urinaria \\
\hline 281310 & Haemophilus influenzae 86-028NP & 1.91 & 38.5 & Meningitis, septicemia, otitis, sinusitis y bronquiti \\
\hline 85962 & Helicobacter pylori 26695 & 1.67 & 38.9 & Inflamación gástrica y úlcera péptica \\
\hline 169963 & Listeria monocytogenes EGD-e & 2.94 & 37 & Listeriosis \\
\hline 272631 & Mycobacterium leprae TN* & 3.27 & 57.79 & Lepra \\
\hline 164513 & Mycobacterium tuberculosis FII* & 4.4 & 65.6 & Tuberculosis \\
\hline 272634 & Mycoplasma pneumoniae MI29* & 0.82 & 40 & Neumonía atípica juvenil \\
\hline 242231 & Neisseria gonorrhoeae FA 1090 & 2.15 & 52.7 & Gonorrea \\
\hline 272831 & Neisseria meningitidis FAMI8 & 2.19 & 51.6 & Meningitis y septicemia \\
\hline 267747 & Propionibacterium acnes KPAI7I202 & 2.56 & 60 & Acné \\
\hline 208964 & Pseudomonas aeruginosa PAOI & 6.26 & 67 & Infecciones oportunistas \\
\hline 295319 & Salmonella enterica subsp. enterica * & 4.59 & 52.2 & Fiebre paratifoidea \\
\hline 216598 & Shigella dysenteriae Sd $197 *$ & 4.59 & 51.10 & Disentería \\
\hline 198215 & Shigella flexneri 2a str. 2457T & 4.6 & 50 & Disentería \\
\hline 93062 & Staphylococcus aureus subsp. aureus COL * & 2.81 & 37 & Síndrome de choque tóxico y fiebre "escarlata" \\
\hline 243276 & Treponema pallidum subsp. pallidum str. Nichols & 1.14 & 52 & Sífilis \\
\hline 345075 & Vibrio cholerae $\mathrm{O} 395 *$ & 4.1 & 47.5 & Enfermedad gastrointestinal \\
\hline
\end{tabular}

* Por razón de espacio se eliminaron organismos del mismo género o especie. Se seleccionaron sólo genomas completos 


\section{Cuadro II}

Genomas representativos de protistas accesibles en la base de datos del NCBI (Julio de 2008). Estas BASES DE DATOS ESTÁN DISPONIBLES EN EL SITIO WWW.NCBI.NLM.NIH.GOV. SE LISTAN CARACTERÍSTICAS GENERALES DEL MICROORGANISMO. LA ID TAXONÓMICA CORRESPONDE A LA BASE DE DATOS DE CLASIFICACIÓN DE ORGANISMOS (TAXBrowser) accesible en el mismo sitio. El tamaño del genoma Se expresa en megabases (Mb). El número CROMOSÓMICO (CROM) SE DETERMINó POR DIVERSOS MÉTOdOS, EN PARTICULAR PFGE.

\begin{tabular}{|c|c|c|c|c|c|c|}
\hline Microorganismo & Subgrupo & ID taxonómica & Tamaño genoma & Crom. & Estatus & Fecha liberación \\
\hline Cryptosporidium hominis & Apicomplexa & 237895 & 8.74 & 8 & Ensamblado & $10 / 27 / 2004$ \\
\hline Cryptosporidium parvum lowa & Apicomplexa & 5807 & 9.1 & 8 & Ensamblado & $03 / 27 / 2004$ \\
\hline Dictyostelium discoideum AX4 & Otros protistas & 44689 & 34 & 6 & Ensamblado & $03 / 03 / 2005$ \\
\hline Eimeria tenella & Apicomplexa & 5802 & 60 & 14 & Progreso & \\
\hline Emiliania huxleyi 1516 & Otros protistas & 2903 & 220 & & Progreso & \\
\hline Entamoeba dispar & Otros protistas & 46681 & & & Progreso & $02 / 11 / 2006$ \\
\hline Entamoeba histolytica & Otros protistas & 5759 & 20 & 14 & Completo & $12 / 09 / 2004$ \\
\hline Entamoeba invadens* & Otros protistas & 33085 & & & Progreso & $02 / 11 / 2006$ \\
\hline Entamoeba moshkovskii & Otros protistas & 41668 & & & Progreso & \\
\hline Galdieria sulphuraria & Otros protistas & I3008| & & 2 & Progreso & \\
\hline Giardia lamblia ATCC 50803 & Otros protistas & 184922 & 12 & 5 & Ensamblado & $03 / 26 / 2003$ \\
\hline Leishmania infantum & Cinetoplástidos & 5671 & & & Progreso & \\
\hline Leishmania major Friedlin & Cinetoplástidos & 5664 & 5.44 & 8 & Completo & $03 / 17 / 1999$ \\
\hline Naegleria gruberi & Otros protistas & 5762 & & & Progreso & \\
\hline Paramecium tetraurelia & Otros protistas & 5888 & & & Progreso & $1 \mathrm{I} / 03 / 2006$ \\
\hline Physarum polycephalum & Otros protistas & 5791 & & & Progreso & \\
\hline Phytophthora infestans & Otros protistas & 4787 & & & Progreso & \\
\hline Phytophthora infestans & Otros protistas & 4787 & & & Progreso & $11 / 15 / 2006$ \\
\hline Phytophthora ramorum & Otros protistas & 164328 & & & Progreso & $09 / 01 / 2006$ \\
\hline Phytophthora sojae & Otros protistas & 67593 & & & Progreso & $09 / 01 / 2006$ \\
\hline Plasmodium berghei strain ANKA & Apicomplexa & 5823 & 26 & 14 & Ensamblado & $12 / 09 / 2004$ \\
\hline Plasmodium chabaudi & Apicomplexa & 5825 & 30 & 14 & Ensamblado & $12 / 09 / 2004$ \\
\hline Plasmodium falciparum 3D7 & Apicomplexa & 36329 & 23 & 14 & Progreso & $11 / 06 / 1998$ \\
\hline Plasmodium gallinaceum & Apicomplexa & 5849 & 25 & 14 & Progreso & \\
\hline Plasmodium knowlesi & Apicomplexa & 5850 & 25 & 14 & Progreso & \\
\hline Plasmodium reichenowi & Apicomplexa & 5854 & & 14 & Progreso & \\
\hline Plasmodium vivax (strain Salvador I) & Apicomplexa & 126793 & 30 & 14 & Progreso & $09 / 20 / 2005$ \\
\hline Plasmodium yoelii yoelii & Apicomplexa & 73239 & 23 & 14 & Ensamblado & $10 / 09 / 2002$ \\
\hline Tetrahymena thermophila & Otros protistas & 5911 & & & Progreso & $02 / 14 / 2005$ \\
\hline Theileria annulata & Apicomplexa & 5874 & 10 & 4 & Progreso & \\
\hline Theileria parva & Apicomplexa & 5875 & 9 & 4 & Progreso & $06 / 30 / 2005$ \\
\hline Toxoplasma gondii & Apicomplexa & 5811 & 30 & 9 & Progreso & $05 / 05 / 2006$ \\
\hline Trichomonas vaginalis & Otros protistas & 5722 & & & Progreso & $05 / 25 / 2005$ \\
\hline Trypanosoma brucei & Cinetoplástidos & 5691 & 26 & 22 & Ensamblado & $08 / 09 / 2003$ \\
\hline Trypanosoma congolense IL3000 & Cinetoplástidos & 5692 & & & Progreso & \\
\hline Trypanosoma cruzi & Cinetoplástidos & 5693 & 34 & & Completo & $07 / / 4 / 2005$ \\
\hline Trypanosoma vivax Y486 & Cinetoplástidos & 5699 & & & Progreso & \\
\hline
\end{tabular}

(enzimas para detección colorimétrica, fluorescencia). El número de moléculas blanco presentes en la muestra determina el número de moléculas de la sonda que se fijan al formato, lo cual determina la intensidad de la señal. La especificidad de la señal obtenida depende del grado de complementariedad entre las dos cadenas de ADN (la sonda y el gen investigado) y su sensibilidad (que se limita al número de copias del gen investigado en el material biológico).

En formato individual, la hibridación es útil para detectar o confirmar los resultados de otras pruebas. ${ }^{48}$
Nuevos desarrollos que usan el principio de hibridación son los microarreglos. ${ }^{49}$ En este formato, las sondas de ADN se imprimen o sintetizan (con formación de celdas) por medios automáticos directamente ${ }^{50}$ sobre soportes sólidos de vidrio o polipropileno y estas secuencias, fijadas en el soporte sólido, se incuban con muestras que contienen el material genético en estudio, previamente marcado, de tal modo que al hibridarse se presenta una señal en la celda reconocida.

En el momento presente, los altos costos de los métodos basados en microarreglos impiden su empleo 


\begin{abstract}
Cuadro III
Bases de datos de genomas de insectos. Existen 57 proyectos de secuencia de genoma, Sólo SE HA COMPLETAdo EL DE DROSOPHILA MELANOGASTER, 3 I SE HALLAN EN FASE DE ENSAMBLADO Y 3 I EN PROCESO. SE LISTAN MICROORGANISMOS REPRESENTATIVOS DE IMPORTANCIA MÉDICA
\end{abstract}

Microorganismo

ID taxonómica $\begin{aligned} & \text { Tamaño } \\ & \text { genoma }\end{aligned}$ Crom. Estatus

Fecha de
liberación

Centro/Consorcio

TIGR Broad Institute

\begin{tabular}{|c|c|c|c|c|c|c|}
\hline Aedes aegypti Liverpool & 7159 & 800 & 3 & Ensamblado & $02 / 11 / 2005$ & $\begin{array}{l}\text { The International Consortium for the Sequencing } \\
\text { of Anopheles Genome Celera }\end{array}$ \\
\hline Anopheles gambiae str. PEST & 180454 & & 3 & Ensamblado & $03 / 22 / 2002$ & Genomics Genoscope \\
\hline Apis mellifera DH4 & 7460 & 200 & 16 & Ensamblado & $12 / 19 / 2003$ & Baylor College of Medicine \\
\hline Bombyx mori (2) & 7091 & 530 & 28 & Ensamblado & $04 / 27 / 2004$ & International Lepidopteran Genome Project \\
\hline Culex quinquefasciatus & 7175 & 540 & 3 & Ensamblado & $04 / 19 / 2004$ & Broad Institute \\
\hline Drosophila melanogaster (varias) & 7227 & 180 & 4 & Completo & $12 / 18 / 2002$ & Berkeley Drosophila Genome Project \\
\hline Nasonia vitripennis AsymCX & 7425 & & 5 & Ensamblado & $05 / 04 / 2007$ & Baylor College of Medicine \\
\hline Rhodnius prolixus & 13249 & 670 & $\mathrm{II}$ & Progreso & & Washington University (WashU) \\
\hline Tribolium castaneum Georgia GA2 & 7070 & 200 & 10 & Ensamblado & $08 / 17 / 2005$ & Baylor College of Medicine \\
\hline
\end{tabular}

en estudios poblacionales; no obstante, esta técnica se ha utilizado para estudios epidemiológicos que incluyen números pequeños de muestras, como la genotipificación de cepas de virus de la inmunodeficiencia humana resistentes a tratamiento, ${ }^{51}$ y para determinar el origen de infecciones sintomáticas y asintomáticas con poliovirus en una población previamente vacunada. ${ }^{52}$

$P C R$. La reacción en cadena de la polimerasa (PCR) es un procedimiento muy sensible que utiliza una polimerasa de ADN; este procedimiento permite amplificar y detectar de manera específica, a partir de una sola molécula blanco, secuencias particulares de ADN. La reacción depende de oligonucleótidos cortos (cebadores o sondas) que tienen la secuencia adecuada (complementaria) para hibridar en los extremos de cadenas sencillas del ADN blanco, las cuales se obtienen mediante la desnaturalización del ADN original. Una vez unida, la sonda sirve como ancla para que la polimerasa inicie la producción de la cadena complementaria a la secuencia blanco, de tal manera que se forman moléculas de ADN de doble cadena. La desnaturalización de este ADN, la hibridación con la sonda y la síntesis de la cadena complementaria con ciclos repetidos permiten la obtención de grandes cantidades de ADN específico del microorganismo investigado, lo cual facilita su detección. El reconocimiento del material producido se obtiene mediante electroforesis en geles de agarosa y la identificación de bandas del tamaño molecular esperado por medio de tinción con bromuro de etidio. La sensibilidad y especificidad de la PCR han permitido el desarrollo de métodos diagnósticos para una gran varie- dad de agentes infecciosos: bacterias, protozoarios, virus y helmintos. ${ }^{53,54}$ La prueba de PCR descrita se conoce como de "punto final", ya que la reacción se detiene hasta que todos los reactivos necesarios para la amplificación se han utilizado. A partir del método básico de PCR se han desarrollado variantes para detectar ADN o ARN, con objeto de hacerlo cuantitativo (véase más adelante) y aplicar sistemas diagnósticos automatizados que realizan el procesamiento de las muestras desde la purificación del material genético hasta su análisis. ${ }^{54}$

Existen numerosas pruebas diagnósticas que usan la PCR con el formato de "punto final"; en éstas, la reacción se realiza en un número predeterminado de ciclos y los productos se analizan por electroforesis. Por ejemplo, las especies de Corynebacterium: C. diphteriae, C. ulcerans y C. pseudotuberculosis, son patógenas sólo cuando producen la toxina diftérica, para lo cual necesitan copias completas del gen tox. Mediante pruebas de PCR se puede reconocer la presencia del gen aun en muestras de pacientes que han recibido antibióticos, en quienes ya no es posible cultivar la bacteria. Sin embargo, en algunas cepas que poseen el gen tox, debido a mutaciones en la región de control del gen, éste no es activo, por lo que los pacientes positivos por PCR aún se los considera como casos presuntivos. ${ }^{55,56}$

La PCR de punto final también se usa para el diagnóstico y clasificación de los parásitos del género Leishmania spp., los cuales poseen una mitocondria modificada llamada cinetoplasto en la que existen dos tipos de moléculas de ADN, los maxicírculos y los minicírculos. En la secuencia de los minicírculos, se 
presentan regiones conservadas y variables, entre las cuales se encuentran algunas específicas de especie/ aislado (oxidasa de citocromo y regiones espaciadoras intergénicas), a partir de las cuales se pueden diseñar pares de oligonucleótidos iniciadores que al amplificar permiten distinguir entre géneros, especies y poblaciones de parásitos. ${ }^{57-59}$ Este método se puede aplicar a diferentes tipos de muestras, como sangre o aspirados de nódulos linfáticos, y en la actualidad se ha probado para la evaluación de la efectividad de nuevos fármacos, ${ }^{59}$ la identificación de portadores asintomáticos y de animales que sirven como reservorios en la naturaleza. ${ }^{60}$

En la PCR multiplex se incorporan a la reacción de amplificación más de un par de sondas específicas para diferentes secuencias blanco. Los fragmentos generados pueden reconocerse por su tamaño o por medio de marcadores incluidos en las sondas. Entre las aplicaciones de este sistema figuran el análisis de muestras en las que hay varias moléculas blanco del mismo organismo, la confirmación de que éste se halla presente, o bien la investigación de forma simultánea de varios patógenos, para lo cual se incluyen sondas específicas para cada microorganismo. La dificultad principal de la PCR multiplex es el diseño adecuado de los oligos con el fin de evitar interacciones inespecíficas entre ellos y reconocimientos cruzados y lograr que los amplicones resultantes se puedan diferenciar unos de otros. Para el diseño de estos cebadores se han desarrollado programas computacionales ${ }^{61}$ que incluyen como elementos de selección secuencias específicas de los patógenos en estudio y composición de éstos para que los procesos de amplificación requieran las mismas condiciones (temperatura de "fusión"). De esta manera se genera un "sistema de tubo único", en el cual se coloca la muestra en un tubo que se cierra con los reactivos de purificación y amplificación y ya no se abre sino hasta obtener el resultado, lo cual reduce el riesgo de manipular muestras peligrosas. ${ }^{62-64}$

Para la identificación de los productos amplificados se han propuesto varias alternativas, además del uso de la electroforesis en agarosa. En un sistema para la detección de productos de PCR en una reacción multiplex, los oligos iniciadores se acoplaron a microesferas, de tal modo que los productos quedaron acoplados a éstas y eran distinguibles en un citómetro de flujo, lo que permitía la automatización de la lectura y la distinción de hasta de 80 blancos diferentes en una reacción. ${ }^{65,66}$ De la misma forma, los oligos pueden acoplarse a moléculas de tamaño diverso disponibles en el comercio (Qiagen Masscode Technology, Qiagen, Hilden, Alemania), con capacidad de distinguir hasta 64 diferentes tamaños y por tanto el mismo número de secuencias específicas. ${ }^{67}$ Otra manera de identificar productos diferentes en una
PCR multiplex consiste en utilizar oligos marcados con faros moleculares (beacons, véase más adelante), los cuales emiten señales fluorescentes a distintas longitudes de onda. ${ }^{68}$ Las pruebas basadas en la PCR multiplex son útiles para reconocer infecciones por patógenos que comparten cuadros sintomáticos comunes; con este propósito se diseñó una prueba para investigar la causa de las fiebres virales hemorrágicas, que incluye sondas para identificar 10 diferentes virus. ${ }^{69}$

Para mejorar la sensibilidad en los ensayos multiplex se aplica también el principio de las reacciones "anidadas", en las cuales la reacción se realiza primero con un juego de iniciadores "externos", que en los primeros ciclos genera un fragmento "grande". En una segunda etapa, el producto de la primera ronda de amplificación se convierte en el molde con un segundo juego de iniciadores que se hallan dentro del producto primario ("anidados"), lo cual asegura la especificidad del amplificado de la primera ronda. ${ }^{68,70}$ Las pruebas diagnósticas veterinarias pueden consultarse en el sitio http:/ / pcr.sdstate.org/.

PCR en tiempo real. Los "puntos finales" de las reacciones de PCR varían entre las muestras debido a la cantidad de ADN blanco presente en éstas. Además, el punto final es difícil de precisar ya que la amplificación, después de una fase exponencial, alcanza una meseta en la que los reactivos comienzan a agotarse. Estas condiciones son determinantes de las limitaciones de este método, entre ellas bajas precisión y sensibilidad, además de que no puede ser cuantitativa. En los métodos de PCR "en tiempo real", las moléculas del fragmento blanco que se amplifican se detectan al mismo tiempo que se generan (durante la fase exponencial de la amplificación), con base en varias estrategias que dependen de moléculas fluorescentes (fluoróforos) cuya emisión es proporcional al número de moléculas producidas, lo que permite hacer la prueba de forma cuantitativa.. ${ }^{11,72}$ Un fluoróforo es una molécula que absorbe radiación de una longitud de onda determinada (luz UV o láser) y luego emite la energía absorbida en forma de luz de una longitud de onda determinada, pero diferente a la empleada para su excitación; esto hace posible su identificación. La utilización de fluoróforos también permite realizar reacciones de amplificación multiplex y detectar cada molécula blanco con un fluorocromo diferente. ${ }^{73}$

El método más sencillo de detección de los productos de PCR en tiempo real es la aplicación de un fluoróforo marcador, como el SYBRgreen, el cual emite fluorescencia cuando se intercala en el surco mayor de la doble hélice del ADN. Otra forma de reconocer productos de PCR en tiempo real consiste en usar los beacons ("faros moleculares"). En este sistema se generan sondas que poseen un fluoróforo "principal" en el 
extremo $5^{\prime}$ y otro fluoróforo de menor intensidad en el extremo 3' con diferente espectro de emisión (beacons). Cuando estas sondas se encuentran como moléculas únicas se pliegan sobre sí mismas y la proximidad de los fluoróforos genera el efecto "FRET" (fluorescence resonance energy transfer), en el cual el fluoróforo secundario apaga la emisión del primario. Al ocurrir la reacción de PCR, el beacon forma parte de las moléculas amplificadas, con lo que el fluoróforo principal se separa del secundario y recupera su fluorescencia, de tal manera que la población de híbridos se puede medir porque su número es directamente proporcional a la magnitud de la fluorescencia. Los beacons pueden prepararse con diferentes fluoróforos, como SYBRgreen ${ }^{\mathrm{TM}}$, fluoresceína (FAM), Texas red, Rhodamina 6G, Cy3, Cy5, entre otros, y DABCYL como apagador, lo que posibilita realizar combinaciones para la detección multiplex. ${ }^{73,74}$ Pueden consultarse las páginas electrónicas http: / / www.mole- cular-beacons.org/ y http:/ / www.appliedbiosystems. com/support/apptech/).

En un ejemplo de aplicación se investigó en muestras sanguíneas humanas la presencia de los genes gag de HIV-1, env HIV-2, tax del virus T-linfotrópico tipo 1 y pol del tipo 2, mediante los juegos de beacons correspondientes, marcados con diferentes fluoróforos; esto permitió determinar la carga viral en las muestras, ${ }^{74,75}$ el método es rápido, sensible, específico y seguro para el operador.

En la PCR llamada TaqMan ${ }^{\mathrm{TM}}$ además del efecto FRET se utilizan las actividades de la polimerasa Taq, que actúa como polimerasa en dirección $5^{\prime}>3$ y como exonucleasa en dirección 3'>5' (figura 4). ${ }^{76,77}$ A diferencia de la reacción de la PCR estándar, en el TaqMan se lleva a cabo una hibridación con una sonda complementaria de una región interna de la secuencia blanco, antes de la amplificación. La sonda interna tiene una temperatura

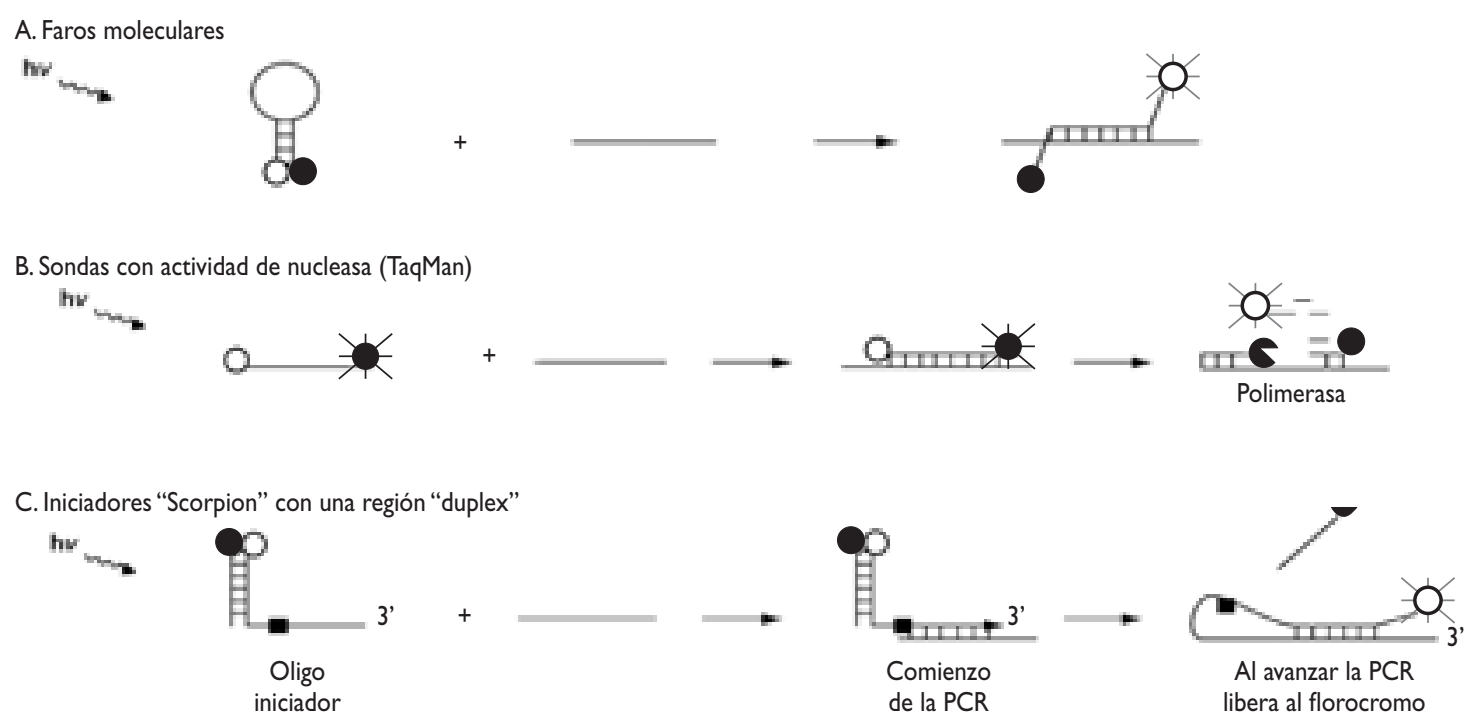

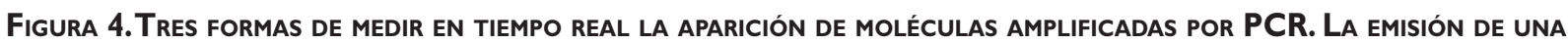
MOLÉCULA FLUORESCENTE PRINCIPAL (FLUORÓFORO, CÍRCULO BLANCO) SE APAGA CUANDO ESTÁ PRÓXIMA A UNA SEGUNDA MOLÉCULA FLUORESCENTE (QUENCHER, CÍRCULO NEGRO) CON UNA ABSORCIÓN Y EMISIÓN DIFERENTE. A. LOS FAROS MOLECULARES SON OLIGOS CON UNA REGIÓN DE APAREAMIENTO QUE FORMA UNA DOBLE CADENA QUE MANTIENE JUNTO AL FLUORÓFORO Y AL QUENCHER Y POR TANTO APAGA LA EMISIÓN DE LA SEÑAL DEL PRIMERO. CUANDO EN EL MEDIO AUMENTA LA CONCENTRACIÓN DE MOLÉCULAS BLANCO SE FORMAN DOBLES CADENAS, SE SEPARA EL FLUORÓFORO DEL QUENCHER Y ELLO LIBERA LA FLUORESCENCIA.

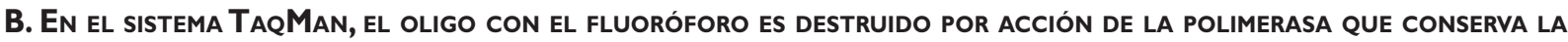
ACTIVIDAD DE NUCLEASA 3'-5' Y SE ACTIVA LA FLUORESCENCIA; LA SONDA TAQMAN, POR SU AFINIDAD MAYOR, SE UNE A SU

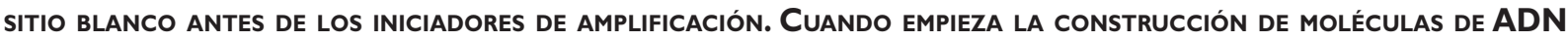
Y LOS CEBADORES SE UNEN, LA POLIMERASA TAQ AVANZA Y, CUANDO ENCUENTRA LA SONDA, LA DEGRADA Y LIBERA LA SEÑAL FLUORESCENTE. C. LOS INICIADORES TIPO ESCORPIÓN ESTÁN FORMADOS POR DOS OLIGOS HIBRIDADOS DE MANERA PARCIAL, CON UNA COLA QUE ES COMPLEMENTARIA DE LA SECUENCIA BLANCO.AL HIBRIDAR LA SECUENCIA ESPECÍFICA CON SU BLANCO E INICIAR LA PCR, LOS FLUORÓforos SE SEPARAN, LO QUE ACTIVA LA SEÑAL 
de "fusión" $10^{\circ} \mathrm{C}$ superior a la de los iniciadores en los extremos y posee en su extremo $5^{\prime}$ un fluoróforo verde (6-carboxifluoresceína, FAM), cuyo espectro de emisión está "apagado" (quenched) por la proximidad espacial de un segundo colorante fluorescente (http:// www. appliedbiosystems.com/support/apptech/). En una reacción de PCR, el primer paso de cada ciclo es un aumento de la temperatura para la desnaturalización de las cadenas de ADN, seguido de un descenso de la temperatura para la renaturalización, durante la cual se unen los iniciadores a los lados de la secuencia blanco. En la reacción TaqMan, durante la renaturalización la sonda TaqMan, en virtud de su afinidad mayor, se une a su sitio blanco antes de que lo hagan los iniciadores de amplificación. Para la fase de síntesis los iniciadores se unen, empieza la conformación de moléculas de ADN y durante el avance de la polimerasa Taq, ésta "choca" con la sonda y por su actividad de exonucleasa la degrada (se "come la sonda", de tal modo que el fluoróforo de la sonda se libera y la señal se activa, lo que posibilita su medición. Se han publicado varios ensayos diagnósticos con base en este método, como el descrito para reconocer Chalmydia trachomatis ${ }^{78}$ y tuberculosis. ${ }^{79}$ En este tipo de prueba también se pueden hacer combinaciones de juegos de iniciadores y sondas con fluoróforos que emitan a distintas longitudes de onda para identificar varios blancos en reacciones multiplex. ${ }^{80-82}$ El sistema Scorpions ${ }^{83,84}$ es similar al anterior en tanto que incluye el juego de fluoróforos, principal y apagador, y el uso de un iniciador para la reacción de PCR, pero con la incorporación covalente de una secuencia adicional formada por un "bloqueador" en la región 5'; empero, a diferencia del anterior, no hay degradación de moléculas. En este formato se han diseñado métodos diagnósticos, como los descritos para Helicobacter pylori ${ }^{85}$ y Micoplasma. ${ }^{86}$

En el mercado ya están disponibles varios estudios diagnósticos basados en la reacción de PCR en tiempo real [sistema Roche Amplicor; (http: / / www.roche.com/ products / product-list.htm? type = diagnostics\&id=29)]; éstos se someten de forma continua a evaluaciones y comparaciones con nuevos productos, aún no comerciales. Por ejemplo, la prueba PCR para Mycobacterium tuberculosis usa como blanco de amplificación una región del ARN ribosomal $16 \mathrm{~S}$ de la micobacteria, con una sensibilidad de 47 a $58.2 \%$ y especificidad de 94 a $97 \%$, según sea el tejido del que se obtiene la muestra. La sensibilidad varía con el tratamiento usado para purificar el material genético y, aunque esta prueba fue superior a los métodos tradicionales, todavía se identificó a un grupo de pacientes en el que no pudo establecerse un diagnóstico definitivo. ${ }^{62}$

\section{Espectrometría de masas y diagnóstico}

En la actualidad, los métodos de espectrometría de masas (MS) disponibles permiten identificar moléculas orgánicas e inorgánicas de forma rápida, confiable y con alto rendimiento. La identificación de proteínas por MS es paralela a la acumulación de secuencias de ácidos nucleicos (genómica) y su control por bioinformática para conocer las proteínas codificadas por ellas y con estas proteínas virtuales hacer experimentos in silico, consistentes en la predicción de los iones que se generan durante la fragmentación en los diferentes sistemas de análisis. En una sola ronda de fragmentación/separación de iones se obtienen "huellas digitales" (gráfica de valores de masa/ carga de los iones, $\mathrm{m} / \mathrm{z}$ ), que permiten identificar a la molécula exacta por comparación con las huellas digitales generadas teóricamente a partir de las bases de datos genómicas. ${ }^{87}$ Con estos estudios es posible identificar biomarcadores de patógenos específicos ${ }^{88-90}$ La MS también puede usarse para identificar secuencias de ADN, lo que permite emplearla para el análisis automatizado y rápido de productos de PCR. ${ }^{91,92}$ Esta aplicación es útil en ensayos de PCR multiplex, como en el sistema denominado Masstag-PCR, en el cual los oligos para realizar la PCR se marcan con grupos químicos de masa conocida (MassTag) y la cantidad de los productos generados durante la amplificación se mide mediante un sistema de espectrometría de masas en fase líquida por la cantidad de las "etiquetas" incorporadas. ${ }^{91}$ Esta técnica se ha aprobado para el diagnóstico diferencial e identificar hasta 22 agentes patógenos de muestras clínicas causantes de enfermedades respiratorias y virales hemorrágicas, con sensibilidad y especificidad elevadas.

\section{Comentarios finales}

La investigación básica mediante genómica y proteómica de microorganismos patógenos proporciona nuevos marcadores biológicos potencialmente útiles para desarrollar métodos de diagnóstico. Para cada enfermedad infecciosa es importante el conocimiento de varios biomarcadores entre las moléculas de los patógenos y entre las moléculas de respuesta de los pacientes, ya que éstas pueden variar a lo largo del proceso infeccioso, según sean las características genéticas de los pacientes, los agentes patógenos y las condiciones ambientales.

El uso de pruebas automatizadas y la inclusión de múltiples marcadores permiten en su formato actual investigar de forma simultánea, rápida y a bajo costo el origen de infecciones que comparten cuadros 
sintomáticos. Por otra parte, es recomendable aplicar un plan estratificado en la investigación de microorganismos patógenos de acuerdo con las condiciones epidemiológicas en cada caso. En consecuencia, cuando la clínica y los informes epidemiológicos sugieren la participación de uno o pocos patógenos es recomendable el uso de PCR de punto final; si no existe suficiente información para circunscribirse a pocos patógenos sospechosos, el PCR multiplex puede ser útil para investigar un número elevado de microorganismos. Los microarreglos pueden ser de utilidad si el PCR multiplex no provee información. ${ }^{93}$

La disposición de genomas completos de los patógenos más comunes ha permitido la identificación y producción masiva de genes y antígenos; las técnicas de biología molecular se emplean para la producción de anticuerpos y sus fragmentos con elevadas especificidad y sensibilidad. Las técnicas para la producción química de moléculas complementarias promete la posibilidad de prescindir ya en el futuro de la producción de anticuerpos y evitar la necesidad de inmunizaciones de animales.

Los sensores basados en moléculas biológicas ofrecen oportunidades sin precedentes para el tamizaje genético y la detección. La tecnología de los microarreglos es útil para el análisis masivo de muestras, aunque implica el uso de una instrumentación muy costosa y algoritmos numéricos complejos para interpretar los datos, de modo tal que dichos métodos se han limitado a los laboratorios de investigación. Sin embargo, los costos disminuyen rápidamente y cabe anticipar que, en un futuro próximo, estarán al alcance de la comunidad médica. ${ }^{94,95}$

\section{Referencias}

I. Barken KB, Haagensen JA, Tolker-Nielsen T.Advances in nucleic acidbase daiagnostics of bacterial infections. Clin Chim Acta 2007;384: I-I I. 2. Kasper DC, Prusa AR, Hayde M, Gerstl N, Pollak A, Herkner KR, et al. Evaluation of Vitros ECiQ immunodiagnostic system for detection of anti-toxoplasma immunoglobulin $\mathrm{G}$ and immunoglobulin $\mathrm{M}$ antibodies for confirmatory testing for acute Toxoplasma gondii infection in pregnant women.J Clin Microbiol 2009;47:164-167.

3. Casiano CA, Mediavilla-Varela M,Tan EM. Tumor-associated antigen arrays for the serological diagnosis of cancer. Cell Proteomics 2006;5: 1745-1759.

4. Thomas WR, Hales BJ, Smith WA. Recombinant allergens for analyzing T-cell responses. Methods 2004;32:255-264.

5. Gamble H,Andrews C, Dubey J,Webert D, Pamley S. Use of recombinant antigens for detection of Toxoplasma gondii.J Parasitol 2000;86:459-462.

6. Coelho AG, Zamarioli LA, Reis CM, Nascimento AC, Rodrigues JS. Gene probes versus classical methods in the identification of micobacteria.J Bras Pneumol 2008;34:922-926.
7. González M, Hassanhi M, Rivera S, Bracho M. Estudio comparativo entre las técnicas de inmunofluorecencia indirecta (IIF) y ELISA en la detección del parvovirus BI9. Invest Clin 2000;41:19-27.

8. Moody A. Rapid diagnostic tests for malaria. Clin Microbiol Rev 2002;15:66-78.

9. Kakkilaya BS. Rapid diagnosis of malaria. Lab Medicine 2003;34:602-608. 10. World Health Organization. The role of laboratory diagnosis to support malaria disease management: focus on the use of rapid diagnostic tests in areas of high transmission. WHO 2006. Disponible en: http://www. int/malaria/docs/ReportLABdiagnosis-web.pdf.

II.WHO/USAID. New perspectives. Malaria diagnosis. Geneva:WHO, 2000 12. Lubell Y, Hopkins H,Whitty C, Staedke S, Mills A. An interactive model for the assessment of the economic costs and benefits of different rapid diagnostic tests for malaria. Malaria J 2008;7:21-32.

13. MacBeath G, Scheiber Sl. Printing proteins as microarrays for highthroughput function determination. Science 2000;289: 1760-1763.

14. Mezzasoma L, Bacarese-hamilton T, Di Cristina M, Rossi R, Bistoni F, Crisanti A. Clin Chemistry 2002;48:121-130.

15. Lonberg N. Human antibodies from transgenic animals. Nat Biotechnol 2005;23: III I- II 25.

16. Miura K, Zhou H, Muratova OV, Orcutt AC, Giersing B, Miller LH, et al. In immunization with Plasmodium falciparum apical membrane antigen I, the specificity of antibodies depends on the species immunized. Infect Immun 2007;75:5827-5836.

17. Chadd HE, Chamow SM. Therapeutic antibody expression technology. Curr Opin Biotechnol 2001;12:188-194.

18. Kellerman SA, Green LL.Antibody discovery: the use of transgenic mice to generate human monoclonal antibodies for therapeutics. Curr Opin Biotechnol 2002;13:593-597.

19. Utsumi S, Karush F.The subunits of purified rabbit antibosy. Biochem 1964;3:1329-1338.

20. Yoo Tj, Roholt OA, Pressman D. Specific binding activity of isolated light chains of antibodies. Science 1967;157:707-709.

2I. Ward ES, Gussow D, Griffths AD, Jones PT, Winter G. Binding activities of a repertoire of single immunoglobulin variable domains secreted from Escherichia coli. Nature 1989;341:544-546.

22. Sundberg EJ, Maruzza RA. Molecular recognition in antibody-antigen complexes. Adv Protein Chem 2002;61:1 19-160.

23. Gibbs W. Nanobodies. Sci Am 2005;293:66-71.

24. Harmsen MM, De Haard HJ. Properties, production, and applications of camelid single-domain antibody fragments. Appl Microbiol Biotechnol 2007;77:13-22.

25. Better M, Chang C, Robinson R, Horwitz A. Escherichia coli secretion of an active chimeric antibody fragment. Science 1998;240:1041-1043.

26. Skerra A, Pluckthun A. Assembly of a functional immunoglobulin fragment in Escherichia coli. Science 1988;240:1038-1041.

27. Bird R, Hardman K, Jacobson J, Johnson S, Kauffman B, Lee S, et al. Single chain antigen-binding proteins. Escherichia coli secretion of an active chimeric antibody fragment. Science 1988;242:423-426.

28. Pokorny NJ, Boulter-Bitzer JI, Hall JC, Trevors JT, Lee H. Inhibition of Cryptosporidium parvum infection of a mammalian cell culture by recombinant scFv antibodies. Antonie Van Leeuwenhoek 2008;94(3): 353-364.

29. Reiter Y, Brinkman U, Byungkook L, Pastan I. Engineering antibody $\mathrm{Fv}$ fragments for cancer detection and therapy: bisulfide-stabilized Fv fragments. Nat Biotechnol 1996; I4:1239-1245.

30. Jia L, Yu J, Song H, Liu X, Ma W, Xu Y, et al. Screening of human antibody Fab fragment against $\mathrm{HBs} A g$ and the construction of its dsFv form. Int J Biol Sci 2008;24;4: 103-I I0.

3I. Shuntao W, Jiannan F, Jianwei G, Leiming G, Yan L, Yingxun S, et al. A novel designed single domain antibody on 3-D structure of ricin A chain remarkably blocked ricin-induced cytotoxicity. Mol Immunol 2006;43:1912-1919. 
32. Rader C, Barbas III CF,Antibody engineering. In: Barbas III CF, Burton DR, Scott JK, Silverman GJ. Phage display: a laboratory manual. Cold Spring Harbor: CSH Laboratory Press, 200 I:3.I-I3.I5.

33. Thie H, Schirrmann T, Paschke M, Dübel S, Hust M. SRP and Sec pathway leader peptides for antibody phage display and antibody fragment production in E. coli. Nat Biotechnol 2008;25:49-54.

34. Mechaly A, Zahavy E. Fisher Development and implementation of a single-chain $\mathrm{Fv}$ antibody for specific detection of Bacillus anthracis spores. M Appl Environ Microbiol 2008;74:8I8-822.

35. Filpula D.Antibody engineering and modification technologies. Biomol Eng 2007;24:20I-2I5.

36. Enkhtuya J, Kawamoto K, Kobayashi Y, Uchida I, Rana N, Makino S. Significant passive protective effect against anthrax by antibody to Bacillus anthracis inactivated spores that lack two virulence plasmids. Microbiology 2006; 152(Pt 10):3103-3110.

37. Grabenstein JD.Vaccines: countering anthrax: vaccines and immunoglobulins. Clin Infect Dis 2008;46:129-I36.

38. Zhou B, Wirsching P, Janda KD. Human antibodies against spores of the genus bacillus: a model study for detection of and protection against anthrax and the bioterrorist threat. Proc Natl Acad Sci USA 2002;99:524I-5246.

39. Binz HK,Amstutz PA, Plücktun A. Engineering novel binding proteins from nonimmunoglobulin domains. Nat Biotechnol 2005;23:1257-1268. 40. Phillips JA, Lopez-Colon D, Zhu Z, Xu Y,Tan W.Applications of aptamers in cancer cell biology.Anal Chim Acta 2008;28;62: I0I-I08. 4I. Wen JD, Gray DM. Selection of genomic sequences that bind tightly to Ff gene 5 protein: primer-free genomic SELEX. Nucl Acids Res 2004;32:el82.

42. Bunka DHJ, Stockley PG.Aptamers come of age-at last. Nat Rev Microbiol 2006;4:588-596.

43. Jayasena SD.Aptamers:An emerging class of molecules that rival antibodies in diagnostics. Clin Chem 1999;45:1628-1650.

44. Collett JR, Cho EJ, Ellington AD. Production and processing of aptamer microarrays. Methods 2005;37:4-15.

45. Carroll S, Grenier J,Weatherbee S. From DNA to diversity. USA: Blackwell Publishing, 2005.

46. Bravata D, McDonald K, Smith W, Rydzak C, Szeto H, Buckeridge $D$, et al. Systematic review: Surveillance systems for early detection of bioterrorism-related diseases. Ann Intern Med 2004;140:910-922. 47. Tang Y-W, Procop G, Persing D. Molecular diagnosis of infectious diseases. Clin Chem 1997:43:2021-2038.

48. Millar BC, Xu J, Moore JE. Molecular diagnostics of medically important bacterial infections. Curr Issues Mol Biol 2007;9:21-39.

49. Southern EM. Microarrays History and Overview. En DNA

Microarrays, Rampal JD. New Jersey: Humana Press, 2001:9-15.

50. Eaucage SL, Caruthers MH. DEoxynucleotide phosphoramidites - a new class of key intermediates for deoxypolynucleotide synthesis. Tetrahedron Lett 1981;22: 1859-1862.

5I. Wilson JW, Bean P, Robins T, Graziano F, Persing DH. Comparative evaluation of three human immunodeficiency virus genotyping systems: the HIV-Genotypipe method, the HIV PRT GeneChip assay, and the HIV-I RT line probe assay.J Clim Microbiol 2000;38:3022-3028.

52. Chersakova E, Laassri M, Chizhikov V, Korotkova E, Dragunsky E, Agol $\mathrm{VI}$, et al. Microarray analysis of evolution of RNA viruses: evidence of circulation of virulent higly divergent vaccine-derived polioviruses. Proc Natl Acad Sci USA 2003;100:9398-9403.

53. leven M. Currently used nucleic acid amplification tests for the detection of viruses and atypicals in acute respiratory infections. J Clin Virol 2007; 40:259-276.

54. Rudi K, Hoidal HK, Katla T, Johansen BK, Nordal J, Jakobsen KS. Direct real-time PCR quantification of Campylobacter jejuni in chicken fecal and cecal samples by integrated cell concentration and DNA purification. Appl Environ Microbiol 2004;70:790-797.
55. Efstrastiou A, Engler K, Mazurova I, Giushkevich T,Vuopio-Varkila J, Popovic T. Current approaches to the laboratory diagnosis of diphteria. J Infect Dis 2000; I8I(Suppl I):SI38-SI45.

56. Kolodkina V,Titov L, Sharapa T, Grimont F, Grimont PA, Efstratiou A. Molecular epidemiology of $C$. diphtheriae strains during different phases of the diphtheria epidemic in Belarus. BMC Infect Dis 2006;6:129.

57. Strauss-Ayali D, Jaffe CL, Burshtain O, Gonen L, Baneth G. Polymerase chain reaction using noninvasively obtained samples, for the detection of Leishmania infantum DNA in dogs. J Infect Dis 2004;189:1729-1733. 58. Mortarino M, Franceschi A, Mancianti F, Bazzocchi C, Genchi C, Bandi C. Quantitative PCR in the diagnosis of Leishmania. Parassitologia 2004;46:163-167.

59. Reale S, Maxia L,Vitale F, Gloriosos N, Caracappa S, Vesco G. Detection of Leishmania infantum in dogs by PCR with lymph node aspirates and blood. J Clin Microbiol 1999;37:2931-2935.

60. Le FichouxY, Quaranta J,Aufeurre J, Lelievre A, Marty P, Suffia I, et al. Ocurrence of Leishmania infantum parasitemia in asymptomatic blood donors living in an area of endemicity in southern France.J Clin Microbiol 1999;37:1953-1957.

6I. Jabado OJ, Palacios G, Kapoor V, Hui J, Renwick N, Zhai J, et al. Nucleic Acids Res 2006;34:6605-66II.

62. Osores F, Nolasco O,Verdonck K,Arevalo J, Ferrufino JC,Agapito $\mathrm{J}$, et al. Clinical evaluation of a $16 \mathrm{~S}$ ribosomal RNA polymerase chain reaction test for the diagnosis of lymph node tuberculosis. Clin Infect Dis 2006;43:855-859.

63. Das S, Pingle MR, Muñoz-Jordan J, Rundell MS, Rondini S, Granger $\mathrm{K}$, et al. Detection and serotyping of dengue virus in serum samples by multiplex reverse transcriptase PCR-ligase detection reaction assay.J Clin Microbiol 2008;46:276-284.

64. Shu PY, Chang SF, Kuo YC, Yueh YY, Chien LJ, Sue CL, et al.

Development of group- and serotype-specific one-step SYBR green

I-based real-time reverse transcription-PCR assay for dengue virus.J Clin Microbiol 2003;41:2408-24I6.

65. Lee WM, Grindle K, Pappas T, Marshall DJ, Moser MJ, Beaty EL, et al. High-throughput, sensitive, and accurate multiplex PCR-microsphere flow cytometry system for large-scale comprehensive detection of respiratory viruses.J Clin Microbiol 2007;45:2626-2634.

66. Edwards MC, Gibbs RA. Multiplex PCR: advantages, development, and applications. PCR Methods Appl 1994;3:S65-S75.

67. Briese T. Palacios G, Kokoris M, Jabado O, Liu Z, Renwick N, et al. Diagnostic system for rapid and sensitive differential detection of pathogens. Em Infect Dis 2005; I :310-313.

68. Templeton KE, Scheltinga SA, Beersma MF, Kroes AC, Claas EC. Rapid and sensitive method using multiplex real-time PCR for diagnosis of infections by influenza a and influenza $B$ viruses, respiratory syncytial virus, and parainfluenza viruses I, 2, 3, and 4.J Clin Microbiol 2004;42:I564-I569. 69. Palacios G, Briese T, Kapoor V, Jabado O, Liu Z,Venter M, et al. Mass Tag polymerase chain reaction for differential diagnosis of viral hemorrhagic fevers. Em Infect Dis 2006;12:692-695.

70. Lam WY, Yeung AC, Tang JW, Ip M, Chan EW, Hui M, et al. Rapid multiplex nested PCR for detection of respiratory viruses.J Clin Microbiol 2007;45:363I-3640.

7I. Mackay IM. Real-time PCR in the microbiology laboratory. Clin Microbiol Infect 2004;10:190-212.

72. Qvarnstrom Y, James C, Xayavong M, Holloway BP,Visvesvara GS, Sriram R, et al. Comparison of real-time PCR protocols for differential laboratory diagnosis of amebiasis.J Clin Microbiol 2005;43:549I-5497. 73. Wagenknecht HA. Fluorescent DNA base modifications and substitutes: multiple fluorophore labeling and the DETEQ concept.Ann N Y Acad Sci 2008; I 130:122-130.

74. Espy MJ, Uhl JR, Sloan LM, Buckwalter SP, Jones MF, Vetter EA, et al. Real-time PCR in clinical microbiology: applications for routine laboratory testing. Clin Microbiol Rev 2006; 19:165-256. 
75. Vet JAM, Marras SA. EDesign and optimization of molecular beacon real-time polymerase chain reaction assays. In: Herdewijn $\mathrm{P}$ (ed.). Oligonucleotide synthesis: methods and Applications. Totowa, NJ: Humana Press, 2004:273-290.

76. Vet J, Majithia A, Marras S, Tyagi S, Dube S, Poiesz B, et al. Multiplex detection of four pathogenic retroviruses using molecular beacons. Proc Natl Acad Sci USA 1999;96:6394-6399.

77. Suzuki N, Yoshida A, Nakano Y. Quantitative analisis of multi-species oral biofilms by Taqman real-time PCR. Clin Med Res 2005;3: I76-185. 78. Schaeffer A, Henrich B. Rapid detection of Chlamydia trachomatis and typing of the Lymphogranuloma venereum associated L-Serovars by TaqMan PCR. BMC Infect Dis 2008;8:56.

79. Takahashi T, Tamura M, Takahashi SN, Matsumoto K, Sawada S, Yokoyama E,et al. Quantitative nested real-time PCR assay for assessing the clinical course of tuberculous meningitis. J Neurol Sci 2007;255:69-76.

80. Lim DV, Simpson JM, Kearns EA, Kramer MF. Current and developing technologies for monitoring agents of bioterrorism and biowarfare. Clin Microbiol Rev 2005; I8:583-607.

8I. Lindegren G,Vene S, Lundkvist A, Falk KI. Optimized diagnosis of acute dengue fever in Swedish travelers by a combination of reverse transcription-PCR and immunoglobulin $\mathrm{M}$ detection.J Clin Microbiol 2005;43:2850-2855.

82. Hart KW,Williams OM, Thelwell N, Fiander AN, Brown T, Borysiewicz LK, et al. Novel method for detection, typing, and quantification of human papillomaviruses in clinical samples.J Clin Microbiol 200I;9:3204-32I2.

83. Schweitzer B, Kingsmore S. Combining nucleic acid amplification and detection. Curr Opin Biotechnol 200 I; 12:2I-27.

84. Hart KW,Williams OM, Thelwell N, Fiander AN, Brown T, Borysiewicz

LK, et al. Novel Method for Detection, Typing, and Quantification of Human Papillomaviruses in Clinical Samples.J Clin Microbiol 200I;39:3204-32I 2.

85. Burucoa C, Garnier M, Silvain C, Fauchère JL. Quadruplex realtime PCR assay using allele-specific scorpion primers for detection of mutations conferring clarithromycin resistance to Helicobacter pylori.J Clin Microbiol 2008;46:2320-2326.

86. Di Marco E, Cangemi G, Filippetti M, Melioli G, Biassoni R.

Development and clinical validation of a real-time PCR using a unimolecular Scorpion-based probe for the detection of Mycoplasma pneumoniae in clinical isolates. New Microbiol 2007;30:4I5-42I. 87. Veenstra T. Mass spectrometry: the foundation of Proteomics. In: Veenstra T,Yates J. (eds.) Proteomics for biological discovery. JWiley and sons 2006: I-18.

88. Burlak C, Hammer CH, Robinson MA, Whitney A, McGavin MJ, Kreiswirth BN, et al. Global analysis of community-associated methicillinresistant Staphylococcus aureus exoproteins reveals molecules produced in vitro and during infection. Cell Microbiol 2007;9:1 I72-1 190.

89. Cowan ML,Vera J. Proteomics: advances in biomarker discovery. Expert Rev Proteomics 2008;5:21-23.

90. Hodgetts A, Levin M, Kroll JS, Langford PR. Biomarker discovery in infectious diseases using SELDI. Future Microbiol 2007;2:35-49.

9I. Blyn LB, Hall TA, Libby B, Ranken R, Sampath R, Rudnick K, et al. Rapid detection and molecular serotyping of adenovirus by use of PCR followed by electrospray ionization mass spectrometry.J Clin Microbiol 2008;46:644-65I.

92. Sampath R, Hall TA, Massire C, Li F, Blyn LB, Eshoo MW, et al. Rapid identification of emerging infectious agents using PCR and electrospray ionization mass spectrometry. Ann NY Acad Sci 2007; I 102:109-120. 93. Lipkin WI. Pathogen discovery. Plos Pathog 2008;4.

94. Drummond TG, Hill MG, Barton J. Electrochemical DNA sensors. Nat Biotechnol 2003;21:1192-1199.

95. Sra KK, Torres G, Rady P, Hughes TK, Payne DA, Tyring SK. Molecular diagnosis of infectious diseases in dermatology. J Am Acad Dermatol 2005;53:749-765. 